\title{
VALPARAÍSO EN CENIZAS: CRISIS DE REPRESENTACIÓN EN LA NARRATIVA DE JACOBO DANKE ${ }^{1}$
}

\author{
VALPARAÍSO IN ASHES: CRISIS OF REPRESENTATION IN THE \\ NARRATIVE OF JACOBO DANKE
}

\author{
Alexis Candia-Cáceres \\ Centro de Estudios Avanzados (CEA), Universidad de Playa Ancha, Valparaíso, Chile. \\ ivan.candia@upla.cl
}

Ana María Cristi

Pontificia Universidad Católica de Chile. Chile. arcristi@uc.cl

\begin{abstract}
Resumen: En el artículo se realiza un análisis del imaginario urbano de Valparaíso presente en las novelas Dos hombres y una mujer. Memorias de un proletario (1933) y La estrella roja (1936). Para esto, se estudia cómo la narrativa de Jacobo Danke, publicada en la década de 1930, pone en crisis la representación tradicional de la ciudad. Utilizando recursos teóricos provenientes de la teoría literaria, la antropología, la filosofía y la historia, se demuestra que, desde la narrativa de Danke, emerge una "ciudad anárquica", caracterizada por el desorden, la disidencia y la hostilidad que marca la apertura del extenso ciclo de decadencia de Valparaíso en el siglo XX.
\end{abstract}

Palabras clave: Jacobo Danke, literatura de Valparaíso, crítica literaria, imaginarios urbanos, siglo XX.

Abstract: In this study, we present an analysis of the Valparaiso's urban imaginary
present in both novels Dos hombres y una mujer. Memorias de un proletario (1933)
and La estrella roja (1936). For this purpose, we study how Jacobo Danke's narrative,
published in the 1930s, puts in crisis the traditional representation of the city. Using
theoretical resources from the literary theory, anthropology, philosophy and history,
we demonstrate that emerges an "anarchic city" from Danke's narrative. The latter is

${ }^{1}$ Proyecto Fondecyt Regular 2018 N ${ }^{\circ} 1181787$ : "Disidencia, desborde y catástrofe en los imaginarios urbanos de Valparaíso (1914-2014)", financiado por el Fondo Nacional de Desarrollo Científico y Tecnológico. Investigador Responsable: Iván Alexis Candia Cáceres. 
characterized by disorder, dissent and hostility that mark the opening of Valparaíso's extensive cycle of decadence in the twentieth century.

Keywords: Jacobo Danke, Valparaiso's literature, Literary criticism, 20th century.

Recibido: 14/04/2019. Aceptado: 20/12/2019.

\section{Introducción}

$\mathrm{V}$

alparaíso, en su condición de ciudad-puerto ha sido, históricamente, un espacio urbano abierto no solo al ingreso y salida de mercaderías, bienes y servicios sino, también, a diversas manifestaciones culturales. De esta forma, se ha transformado en una puerta de entrada de nuevas perspectivas y sensibilidades que amplían, a todas luces, el panorama intelectual nacional. En la década de 1930 irrumpieron estéticas que, desmarcándose de las tendencias literarias que habían predominado hasta entonces en las letras nacionales (realismo, naturalismo y criollismo), promovieron el desarrollo de una literatura que, por una parte, fue cercana a las vanguardias y que, por otra, adoptó ciertos elementos del realismo socialista. De ahí que Adolfo de Nordenflycht sostenga que "Valparaíso daba un giro en la búsqueda de otras imágenes identitarias" (2011: 62). Adicionalmente, es necesario agregar que la literatura de esa época evidencia el tránsito del "Valparaíso sublime", marcado por su hegemonía económica e influencia política y cultural, hacia una ciudad que está signada por la precariedad y, asimismo, por la nostalgia hacia una expansión económica perdida de manera definitiva tras la crisis económica de 1929.

De los escritores porteños que nutren este imaginario, Jacobo Danke ${ }^{2}$

${ }^{2}$ Jacobo Danke es el seudónimo utilizado por Juan Cabrera Pajarito (1905-1963). Danke fue un escritor porteño cuya propuesta estética se desarrolló en la poesía y la narrativa. La temática que privilegió en sus escritos fue la ciudad de Valparaíso: el mar, los cerros y el puerto. Desde muy temprano desarrolló una poesía de marcada tendencia modernista, simbolista e imaginista. Interesado por la vanguardia y la política fundó, junto a Oreste Plath, la revista Gong! Tablero de arte (1929) donde participan escritores e intelectuales chilenos y latinoamericanos como Pablo Neruda, José Carlos Mariátegui, Cesar Vallejo, etc. Su interés por las vanguardias y el realismo social se refleja en su contribución en la Generación Literaria de 1938 donde, junto a Nicomedes Guzmán, Andrés Sabella, Pepita Turina, Héctor Barreto, entre otros, intenta reconfigurar la narrativa nacional, dando a conocer espacios y subjetividades que habían sido poco considerados en la producción lite- 
se destaca por explorar en sus creaciones los intersticios de la realidad que, escasamente, se presentaban en la narrativa nacional, una realidad que, según Salvador Reyes, molesta y saca de rutina a los críticos (1956: 133-134). Esta perspectiva da cuenta de una "ciudad anárquica": un espacio que está sometido a la hostilidad climática y a las múltiples tensiones sociales que emergen tras el colapso económico. Se trata de una ciudad cuyos relatos ya no son protagonizados por sujetos pertenecientes a los sectores altos o medios altos -nacionales o extranjeros- sino, más bien, por los excluidos del imaginario nacional. Dos hombres y una mujer. Memorias de un proletario ${ }^{3}$ (1933) y La estrella roja (1936), textos narrativos que serán analizados en este estudio, relatan, en definitiva, un Valparaíso sufriente, desafiante y combativo.

A pesar de la riqueza que se advierte en la propuesta literaria de Jacobo Danke, los estudios en torno a su narrativa son escasos. Los análisis que se han efectuado sobre sus novelas se desarrollan, usualmente, dentro de estudios historiográficos sobre literatura chilena, donde la obra de Danke constituye una parte complementaria del panorama artístico y literario del siglo XX. Esta situación se evidencia, también, aunque con mayores matices, en análisis de crítica literaria periodística, donde su obra se examinó con mayor profundidad. Desde ambos registros, es posible mencionar que tanto su poesía como su narrativa son estudiados desde la estrecha relación que establece su escritura con el mar, el puerto de Valparaíso y el profundo sentido humano y existencial de sus habitantes.

Oreste Plath (1939) enfatiza la composición sencilla de la obra de Jacobo Danke. Para Plath resulta interesante dilucidar las resonancias marineras que envuelven a su producción literaria, considerando que estas logran sacar a la luz los aspectos más valiosos del paisaje y de la vida de Valparaíso. Posteriormente, Ricardo Latcham (1945) visualiza la narrativa de Danke como luminosa y positiva. El crítico literario sostiene que la narrativa del escritor ha logrado superar el realismo con el que, hasta la fecha, se describía usualmente a la ciudad. El puerto adquiere, en este sentido,

raria chilena, tales como el pueblo obrero, la vida del conventillo, los cerros porteños, etc.

${ }^{3}$ Dos hombres y una mujer. Memorias de un proletario es un libro que está compuesto por la novela homónima, el poema "Iconoclasta" y el relato "El agitador". La triada de textos tienen profundas afinidades éticas y estéticas. Lo anterior, sumado a la decisión del propio Danke, nos hacen tratar el material como un conjunto. 
una nueva dimensión fantasmagórica: se describe entre nieblas, ensueños y metáforas que logran mezclar el realismo con la imaginación. Esta perspectiva es compartida, también, por Raúl Silva Castro (1945), al destacar la figura del puerto en la narrativa de Jacobo Danke. Según el crítico, la ciudad que describe el escritor porteño se presenta como un escenario nebuloso que permite visualizar a personajes que se sitúan bajo el velo del humo y la niebla, o bien en ambientes interiores tamizados. Una situación similar destaca Mario Osses (1952) al sostener que la obra de Danke está compuesta por ritmos oceánicos que se entrecruzan con la suavidad y la violencia. Destaca la vida de los habitantes de Valparaíso, y, sobre todo, la pluralidad de matices que estos múltiples personajes cotidianos entregan a la narrativa de Danke. Andrés Sabella (1946) y Julio Mondaca (1957) aseveran que la obra de Danke se caracteriza por sacar a la luz crepúsculos que logran "desliteralizar" la escritura en torno al mar y la ciudad de Valparaíso, concediéndole una energía verbal que conjuga el territorio marítimo con sus habitantes.

Julio Orlandi (1946) analiza, en tanto, a la representación de Valparaíso en la obra de Danke a partir de la relación que se gesta entre la tierra y el hombre. Orlandi apela a la imagen de un Valparaíso ceniciento y gris que se entrecruza con la vida de los hombres y mujeres que viven y sueñan en la ciudad-puerto. Posteriormente, Leoncio Guerrero (1963) asevera que la narrativa de Danke permite conocer la vida errabunda de los cerros de Valparaíso, toda vez que sus obras cuentan los acontecimientos dramáticos de las poblaciones populares y de los bajos fondos. María Isabel Fernández (2012) matiza esta perspectiva, en tanto, al sostener que la obra de Danke plasma un escenario porteño que se debate entre la luz y la sombra, la maravilla y la realidad. Con todo, la obra literaria de Danke es percibida como una apuesta creativa que logra tamizar diferentes aspectos de la vida en Valparaíso.

Así pues, el siguiente artículo tiene como objetivo analizar el imaginario urbano de las novelas de Jacobo Danke. Valparaíso es representado como una ciudad hostil tanto por las adversas condiciones climáticas como por el decaimiento producido por una crisis económica que la desmarca del retrato de armonía y progreso que detentó en la segunda parte del siglo XIX y en las primeras décadas del siglo XX. De esta forma, se conforma una "ciudad anárquica", es decir, un espacio urbano donde prima un orden dé- 
bil, en el que el caos desafía a las estructuras sociales, culturales y políticas, transgrediendo las directrices que siguieron siendo parte importante de las urbes continentales.

\section{Estrella gris}

La narrativa de Jacobo Danke contribuye a desmantelar la representación del "Valparaíso sublime" que diversos escritores, entre los que destaca Joaquín Edwards Bello, Pablo Neruda, Carlos Casasús, entre otros, conformaron de la ciudad. "Valparaíso sublime" es un concepto acuñado por Edwards Bello que da cuenta del imaginario porteño que emerge como consecuencia del desarrollo económico, la apertura cultural y la preponderancia política que adquiere la urbe en la segunda parte del siglo XIX y que se extiende hasta las primeras décadas del siglo XX. Ciertamente, ese contexto económico, histórico y cultural generó una literatura que celebró un espacio urbano marcado por la consolidación de la cultura emprendedora, la liberalización de las costumbres, la influencia de la inmigración -británica y francesa, mayoritariamente- que generó un ambiente cosmopolita, todos rasgos que terminaron elaborando, en la perspectiva de Edwards Bello, un espacio signado por un "secreto de belleza" (1986: 128).

$\mathrm{Al}$ igual como el contexto influye de manera decisiva en la construcción del "Valparaíso sublime", Jacobo Danke efectúa una "narrativa situada", es decir, una escritura que dialoga de manera estrecha con las condiciones económicas, sociales y culturales de la época, las que, en consecuencia, representan la transformación que experimenta Valparaíso debido a una coyuntura que daña su posición geopolítica:

Valparaíso experimenta a partir de 1913 un progresivo deterioro económico y social que lo lleva a perder su posición hegemónica, siendo relegado a un rol secundario en la circulación de la riqueza y del poder en Chile. Existen al menos cinco hechos que resultan fundamentales para detener el auge que venía experimentando Valparaíso: 1) La apertura del Canal de Panamá en 1913; 2) La Primera Guerra Mundial; 3) La inauguración del puerto de San Antonio; 4) La crisis del 29’; 5) El cambio de firmas a Santiago. (Candia-Cáceres $\mathrm{S} / \mathrm{N}$ ) 
El proyecto escritural de Danke refleja la recesión económica, la precariedad laboral y la tensión social que irrumpe en la ciudad, proyectando, en definitiva, la imagen de una ciudad en crisis. La inestabilidad socio-política de Valparaíso se evidencia, por ejemplo, en La estrella roja ${ }^{4}$ donde el escritor evidencia un escenario urbano inestable, ad portas del caos y el desconcierto de sus habitantes:

El puerto estaba deprimido por la crisis. Las firmas comerciales quebraban unas tras otras. La cesantía comenzaba a lanzar sus ejércitos de hambrientos a la calle. Lo que hasta ayer fuera una bahía trajinada de mástiles y perezosos humos, ahora sólo era un brazo de mar despojado de sus habituales ornamentos: un desván de donde se pudrían como trastos inútiles el dique, la chata maestranza y la lavandera. [...] Valparaíso languidecía bajo la ola depresiva que abultaba sus pechos en Europa y Estados Unidos y venía a rematar, arrolladoramente, en las costas sudamericanas. (1936: 111)

Danke describe una ciudad desesperada. La antigua estabilidad del Gran Puerto es remplazada por el caos y la depresión, situación que permite al escritor servirse de las tonalidades grisáceas del ambiente marino para describir a una ciudad en declive. De hecho, en Dos hombres y una mujer. Memorias de un proletario ${ }^{5}$ Jacobo Danke plasma una ciudad que sobreviene en una atmósfera sombría, la cual entorna la imagen de una urbe fría y sujeta al vendaval, donde el viento "retoza la población bajo su avalancha y desentumece el amontonamiento de las casuchas distribuidas al borde

\footnotetext{
${ }^{4}$ En La estrella roja Danke desarrolla una escritura lúdica, íntima y fragmentaria. A pesar de ser catalogada como una novela poco desenvuelta, confusa y curiosa (Silva Castro, 1960: 364), resulta interesante considerar que el texto se caracteriza por usar una estética narrativa sincrónica que privilegia el acontecimiento antes que el relato lineal. El uso de esta estética posibilita observar al puerto y sus habitantes desde varios ángulos, siendo el recuerdo, la pieza clave que permite relacionar aquellos fragmentos dentro de un mismo corpus narrativo.

${ }^{5}$ Dos hombres y una mujer. Memorias de un proletario comienza con una nota aclarativa en la que se especifica que dicho texto no es el resultado de la ficción, sino que, por el contrario, responde a las memorias del fundador de la "Unión Sindicalista Metalúrgica" de Valparaíso. Esta nota da cuenta de las circunstancias en las que dicho escrito llegó a las manos de Danke y la razón por la cual él se encarga de publicarlo. Así, firmada con sus iniciales, la primera página de la novela logra poner en juego la ambivalencia de un texto verídico, en tanto posibilita el desdoblamiento de la obra en la apariencia de una memoria y en la creación de un texto ficticio.
} 
del barranco" (1933: 23) y "el mar se encabrita, el viento bufo en su bocina lateral y el chubasco brota sobre los tablones del muelle" (1933: 40). Danke elabora, en definitiva, un espacio pincelado con tonos invernales que ponen de manifiesto la perspectiva de un hombre desolado:

$\mathrm{Al}$ amanecer, la lluvia voltea contra los malecones, desaloja el sueño de los edificios a medida que se flota los párpados la mañana. Llueve parcial y unánimemente, y un día ceniciento empezará a revolcarse en el lodo de los charcos y en la contrariedad de los vagabundos que acostumbran a tomar posesión del muelle, acodándose en la orilla del mar. (1933: 55)

A diferencia de la representación del "Valparaíso sublime", cuya tonalidad permeó, incluso, representaciones posteriores de la ciudad y que se sintetizan en el siguiente verso del vals "La joya del pacífico": "Eres un arcoíris de múltiples colores/ tu Valparaíso puerto principal”; Danke elabora, más bien, una ciudad monocromática que subraya la atmosfera gris que se despliega en la ciudad, cuya densidad nebulosa parece comprimir a sus espacios y habitantes. Así, se aprecia, por ejemplo, en los recorridos de Pablo en La estrella roja:

Había comenzado a caer una menuda garúa y una espesa niebla se arrojaba contra la ciudad desde el mar amortajado por la blanquecina camanchaca. Apuró la marcha tiritando de frío, sintiendo que los pies se le mojaban al pisar el húmedo asfalto de las aceras, tenía agujereadas las suelas de los zapatos y al andar se le escocían las plantas como si se hubiese frotado con algo irritante y áspero. (1936: 91)

La narrativa de Danke configura una ciudad presa de un clima hostil. En Dos hombres y una mujer se muestra la violencia que parece apoderarse de uno de los extremos de la ciudad: "Ahora la neblina se arrastraba como un lacayo en la superficie del mar extenso y múltiple. El faro de Punta Ángeles rugía en medio de aquella cerrazón blanca. Desamparadas gaviotas graznaban junto a los remolcadores y los faluchos" (1933: 61). En este sentido, es el mar el elemento de la naturaleza que, en mayor medida, se ve alterado por el ambiente de Valparaíso. Lejos del nombre dado al océano que lo alberga, las aguas de Valparaíso parecen agitadas por una fuerza incontenible: "Al fondo, con una furia satánica, el mar se estrellaba contra los pilares del muelle” (1933: 60). La estrella roja reitera, además, la rude- 
za de un mar que levanta amenazas de naufragios y destrucción: "Los días eran una constante sucesión de brumas y tristezas. Valparaíso, recodo de sugerencias invernales y duro lecho de huracanes coléricos. Asentados en el mar de estaño, el dique y la chata-maestranza de la Compañía Inglesa” (Danke, 1936: 44-45).

No se puede pasar por alto que Danke conforma una imagen urbana, en términos climáticos, marcadamente invernal, fría y dura, que no se condice con la realidad de una ciudad que tiene un clima mediterráneo fresco, con cuatro estaciones diferenciadas y que alterna inviernos húmedos con veranos secos y tibios. Lo anterior, se explica porque el autor de La estrella roja diseña un imaginario urbano que comprende, tal como plantea García Canclini, una "construcción imaginaria" (1995: 51) que da lugar a la elaboración de un espacio soñado, pensado, deseado que no siempre guarda relación con las características reales: "La ciudad se vuelve densa al cargarse con fantasías heterogéneas. La urbe programada para funcionar, diseñada en cuadrícula, se desborda y se multiplica en ficciones individuales y colectivas" (García Canclini 1999: 107). Armando Silva complementa la aproximación de García Canclini al sostener que los imaginarios "se tornan un camino excepcional para entender el espacio, no solo como geografía, sino como historia y cultura. Quizá lo que más puede darnos un estudio de los imaginarios es la colocación del ciudadano en su proyección al pasado y entonces cómo desea su futuro" (2000: 311). Para Silva, el imaginario urbano es "aquella impresión conseguida colectivamente en un alto nivel de segmentación imaginaria de su espacio" (2003). La imagen urbana es la dimensión más profunda de la vida en la ciudad: "corresponde a las formas mentales que van apareciendo en el hacer colectivo: aquello que hace que un sitio sea marcado como ciudad del placer, aquel otro como zona de terror o peligro y uno nuevo como el lugar erótico de la urbe. En el trasfondo lo imaginario se nutre del fantasma" (2003). Silva profundiza en su noción de fantasmas urbanos al sostener que se definen como: "aquella presencia indescifrable de una marca simbólica de la ciudad, vivida como experiencia colectiva, de todos o de una parte significativa de sus habitantes, por la cual nace o se vive una referencia de mayor carácter imaginario que de comprobación empírica" (2000: 113).

En esta dirección, Danke representa la metamorfosis del imaginario urbano de la ciudad, el que, tras la debacle económica y social, da paso a una 
ciudad de masas, pobre y en permanente crisis. Valparaíso aparece como una ciudad pendular en la que los personajes se mueven entre las casas situadas en lo alto de los cerros y las maestranzas. Nicomedes y Anselmo de Dos hombres y una mujer. Memorias de un proletario y Pablo de La estrella roja recorren la distancia que media entre un punto y otro, poniendo de manifiesto cómo la vida se limita a las exigencias laborales y a la recuperación de las energías en el hogar:

Vivían a la orilla de cerro, y Pablo cada vez que bajaba por el sendero hacia el mar, se detenía a contemplar las altas chimeneas de la Maestranza y de la Refinería. En la primera trabajaba su padre, y en la segunda él sabía que allí se elaboraba el aceite de ballena. (Danke, 1936: 58)

Los permanentes recorridos de los personajes de Danke por Valparaíso elaboran lo que Michel de Certeau denomina como una ciudad transhumante, o metafórica que "insinúa así en el texto vivo de la ciudad planificada y legible" (2010: 105). De Certeau establece, en este sentido, una analogía entre el acto de caminar y el de enunciación, los que operan sobre el sistema urbano y los enunciados realizados, respectivamente:

\begin{abstract}
Al nivel más elemental, hay en efecto una triple función "enunciativa": es un proceso de apropiación del sistema topográfico por parte del peatón (del mismo modo que el locutor se apropia y asume la lengua); es una realización espacial del lugar (del mismo modo que el locutor se apropia y asume la lengua); en fin, implica relaciones entre posiciones diferenciadas, es decir "contratos" pragmáticos bajo la forma de movimientos (del mismo modo que la enunciación verbal es "alocución", "establece al otro delante" del locutor y pone en juego contratos entre locutores). El andar parece pues encontrar una primera definición como espacio de enunciación. (2010: 109-110)
\end{abstract}

Esta reflexión es doblemente interesante para analizar la narrativa de Danke, debido a que nos encontramos con textos literarios donde los personajes caminan para enunciar, precisamente, una ciudad particular. Así, Danke se apropia -seleccionando, excluyendo y priorizando- de ciertos signos de Valparaíso, lo que se aprecia, sobre todo, en los extremos de la construcción pendular anunciada previamente, es decir, la casa y la maestranza. 
Las casas porteñas constituyen asentamientos precarios que están situados en las partes altas de los cerros. Se trata de conjuntos habitacionales pequeños que se balancean en los barrancos, viven en las alturas buscando asilo para la pobreza (Danke, 1974: 62). Tanto en La estrella roja como en Dos hombres y una mujer es posible apreciar esta clase de construcciones: "Vivían a la orilla del cerro, en una casa que ejecutaba verdaderos prodigios de equilibrio para no rodar al fondo del barranco" (1936: 60); "La ventana da al barranco, el límite en hondo, que separa la casa de las vallas del mar. Abierta, franquea la entrada a la invasión de la noche, y yo sé que Hortensia no la abría porque la noche y el mar son indefiniblemente tristes" (1933: 14). Danke plasma la cotidianidad transcurrida en los cerros, una cotidianidad que muestra a una clase obrera que, al igual que sus casas, hace esfuerzos para sortear la precaria situación económica y social que enfrenta como consecuencia de la inestabilidad laboral y de la recesión económica porteña de la década de 1930.

En el otro extremo del péndulo porteño se encuentran las maestranzas. Los obreros descienden desde sus casas a fábricas que constituyen espacios diseñados para la explotación de la fuerza humana. Ciertamente, resulta interesante la descripción nocturna que efectúa Danke de uno de esos espacios, debido a que subraya el carácter ominoso y sucio de un área diseñada para la producción de mercancías al menor costo posible: "La maestranza dormida al pie del cerro. La noche sale de ella evacuándola, con un collar de óxido, manchada de orín" (1933: 37). La estrella roja complementa y profundiza la descripción efectuada por Danke con antelación. Principalmente, porque la novela da cuenta del engranaje capitalista en el que están situados los obreros, subrayando sus duras condiciones laborales, las que no están en relación ni con el sueldo ni con los beneficios obtenidos por las funciones desempeñadas:

Allí la vida adoptaba aspectos insospechados de brutalidad y rudeza. Los individuos se reconcentraban física y moralmente para no escatimar un solo esfuerzo de su calidad de proletarios, de objetos dóciles a la férula inquisidora del deber ineludible... Eran los accesorios de una máquina paradójicamente complicada que exigía el máximum de rendimiento, la mayor suma de energías musculares. (1936: 70, cursivas nuestras)

No deja de ser llamativa la descripción de Danke, sobre todo, por sus 
resonancias foucaultianas al plantear, cuarenta años antes de la publicación de Historia de la sexualidad, la idea del cuerpo como una máquina orientada a lograr la máxima eficiencia. La narración de Danke anticipa, en efecto, uno de los postulados centrales del cruce entre poder y capitalismo sostenidos por Michel Foucault. En el primer volumen de la Historia de la sexualidad. La voluntad de saber el teórico francés define a la "anatomopolítica del cuerpo humano" como la noción del "cuerpo entendido como máquina” (2008: 131) que apunta a: "el aumento de sus aptitudes, la extorsión de sus fuerzas, el crecimiento paralelo de su utilidad y su docilidad, su integración en sistema de control eficaces y económicos, todo ello quedó asegurado por procedimientos de poder característicos de las disciplinas” (2008: 131). De esta forma, el cuerpo se pone al servicio de un sistema económico -el capitalista- que demanda un crecimiento constante y progresivo de los sistemas de producción. Más allá de las condiciones laborales, de las molestias físicas, del agotamiento, los cuerpos son considerados como parte de un engranaje que no puede cejar en sus esfuerzos por acrecentar la productividad económica. Así, por ejemplo, se puede apreciar en la labor que desempeña Pablo con su padre en un carbonero en La estrella roja:

\begin{abstract}
A las diez, el trabajo bullía fragorosamente a bordo del carbonero. Colocado de espaldas debajo de las literas destinadas a la tripulación de la nave, Pablo remachaba las puntas de los clavos que su padre iba introduciendo con extraordinaria rapidez desde la parte de arriba. Su incómoda posición le molía los huesos, y los estruendosos martillazos hacían de sus sienes y sus tímpanos latiesen violentamente a cada golpe descargado en la madera. (1936: 77)
\end{abstract}

La sobreexplotación del trabajo -término de Rosa Luxemburgo- en la narrativa de Jacobo Danke responde a la implementación y al desarrollo de un sistema capitalista que, en términos de Grínor Rojo, necesita "crecer continuamente" (2006: 107). De esta forma, el capitalismo persigue, tal como muestra Rojo, no obtener "ganancias en oro constante y sonante, sino la obtención de ganancias en una progresión cada vez mayor” (2006: 109), lo que, por cierto, está sujeto a una variable central: disponer de mano de obra barata. Si a eso agregamos que en la década de 1930 el sistema de protección social era mucho más débil que en la actualidad, es dable sostener que nos encontramos en un escenario que propicia la máxima consecución 
de ganancias sobre la base de mínimas condiciones laborales.

Danke extrema, en esta dirección, los efectos de la exigente carga laboral de los operarios. Al menos existen dos momentos en los que es posible apreciar esta situación. En primer término, se encuentra la muerte del padre de Pablo en La estrella roja, quien, tras una vida marcada por "la furia de las tormentas cotidianas y [...] los embates de la miseria mañosamente enclaustrada en su casa; los cuales fueron tallándole a golpes de hacha el temple físico y a rigor de látigo la fibra ética" (1936: 115), se enferma y cae, irrevocablemente, en la cama. Cerca de la muerte, realiza la siguiente afirmación: "Joderse durante cincuenta años para morir así, como un perro" (1936: 117). La afirmación del anciano no solo pone de manifiesto la aciaga reflexión retrospectiva acerca de su vida laboral, sino que subraya, además, el sinsentido de poner su energía y su cuerpo al servicio de un sistema de producción incapaz de retribuirle con una buena calidad de vida. Adicionalmente, no se puede soslayar que el personaje utiliza la misma expresión que K. de El Proceso de Franz Kafka cuando, al ser asesinado en el desenlace de la novela, realiza la misma aseveración:

Pero uno de los señores lo cogió por la garganta, mientras el otro le clavaba repetidamente el cuchillo en un costado, a la altura del corazón. Con la mirada de un moribundo, observó a los dos señores inclinados muy cerca de su rostro, que contemplaban su fin mejilla contra mejilla. -iComo un perro! dijo, como si la vergüenza le hubiera vencido finalmente. (2014: 571, cursivas nuestras)

La alusión a Kafka intenta destacar la epifanía que el personaje de $L a$ estrella roja siente, al igual que K., ante la inminencia de la muerte: el absurdo. Mientras K. siente vergüenza por la aplicación de una condena que no tiene ningún asidero legal y que, además, es resuelta irregularmente por un sistema judicial paralelo, el padre de Pablo experimenta una sensación análoga por desperdiciar su vida al servicio de la maestranza. Tanto el padre de Pablo como K. comprenden, antes de morir, que dilapidaron su tiempo y fuerzas en sistemas -económicos y judiciales- que conceden escaso valor a la vida humana.

En segundo término, es posible considerar las débiles medidas y protocolos de protección de los trabajadores en Valparaíso, lo que, en La estrella roja, se aprecia en las nulas medidas de seguridad que existían en el 
tratamiento de metales durante la década de 1930. En este sentido Danke plasma la historia de los "picasales", es decir, de los adolescentes que les retiraban el óxido a los navíos:

un ejército de muchachos harapientos y sucios se habían embarcado sobre unas pequeñas balsas y navegaban alrededor del barco, escobillándole enérgicamente el casco, a fin de despojarlo de las capas de óxido que en el largo contacto con el mar había ido adhiriéndosele. [...] más tarde se enteró de que casi todos esos muchachos, a quienes en las faenas marítimas denominaban "picasales", estaban condenados a morir tuberculosos, a causa del mortífero polvillo que aspiraban durante el trabajo. (1936: 80-81)

No es casual que Danke incluyera la historia de los "picasales" en $L a$ estrella roja, debido a que la tuberculosis es una enfermedad asociada, tradicionalmente, a la miseria, las falencias en materia de vivienda y las brutales condiciones laborales. De hecho, Tania Herrera y Victorino Farga plantean en relación a la tuberculosis que desde el siglo XIX: "la causa de la enfermedad se atribuía a factores sociales, porque claramente atacaba con más fuerza a la población más desvalida” (2015: 228). Danke utiliza a la enfermedad como un signo de la precaria situación laboral, social y económica que enfrentan los porteños a mediados de la década de 1930.

Los conflictos sociales en la narrativa de Danke se resuelven, según evidencian las acciones de la clase obrera, a través de la huelga, esto es, la exposición de los cuerpos en la calle, transgrediendo el espacio público y exigiendo solventar necesidades básicas para la sobrevivencia. Dos hombres y una mujer. Memorias de un proletario (1933) y La estrella roja (1936) ponen de manifiesto conflictos al interior de las maestranzas o del puerto que arrancan en la búsqueda de mejores condicionales laborales. De esta forma, la propuesta de Danke pone de manifiesto el carácter reivindicador y transformador de trabajadores que desean alterar sus condiciones materiales y vitales, lo que se muestra en los versos iniciales del poema "Iconoclasta" de Dos hombres y una mujer: "Haced del metal de los campanarios/ hebillas para vuestros cinturones/y herrajes para las cabalgaduras/ iDestruid tal sinfonía de los dioses!” (1933: 57). A lo anterior se suma la voluntad desacralizadora que exhiben los versos obreros, al procurar que se colme de sentido y utilidad práctica el metal destinado a congregar a los 
fieles. De esta forma, es posible argüir que la narrativa de Danke asume que la literatura es lo que resiste, tal como plantean Deleuze y Guattari, es decir: "resiste a la muerte, a la servidumbre, a la infamia, a la vergüenza" (2002: 272).

Bajo esta perspectiva, Danke narra tanto los triunfos como los fracasos de los movimientos sindicales. Dos hombres y una mujer revelan, en primer término, un proceso revitalizador para los trabajadores en la medida que, tras el impacto de las movilizaciones, la empresa se abre a mejorar sus condiciones:

El salón de asambleas de la Confederación, desbordaba de gente jubilosa. Había un barullo ensordecedor y unos a otros se felicitaban con gran algazara. Los que formábamos la comisión que había enfrentado a los representantes patronales, estábamos atareadísimos en la confección de un informe; en él detallábamos nuestra actuación y concluíamos exponiendo que la compañía se allanaba a conceder un aumento de un veinte por ciento. iEl triunfo nos había sonreído!. (1933: 47)

En segundo término, es posible considerar el desenlace de la misma novela, sobre todo, por el fin que encuentra Ordóñez, fin que anticipa algunos de los eventos más violentos de la historia de Chile: la instalación de campos de concentración en el país. Tras el término de las movilizaciones, el trabajador es detenido por las fuerzas policiales y "neutralizado", al igual que otros sujetos, en su condición de amenaza al régimen:

En la noche, un vaporcito partió con veinticinco confinados, rumbo a la isla de Pascua. Los agitadores, los políticos profesionales, los anarquistas todos los que podían representar un peligro para el tirano que había usurpado el poder, comenzaron a ser quitados de en medio, Anselmo Ordóñez fue uno de los primeros. Pero él no volvió nunca más. (1933: 67)

Danke hace operar su propuesta literaria de manera análoga a la concepción planteada por Kafka a Max Brod en una carta escrita en 1912: "El arte es un espejo que se adelanta, como a veces los relojes” (Deleuze y Guattari, 2002: 46). Principalmente, porque Ordóñez es en estricto rigor no solo un prisionero político sino, sobre todo, un desaparecido, práctica que se masificará a partir de las políticas implementadas por la dictadura 
cívico-militar liderada por Augusto Pinochet en Chile.

Ahora bien, es interesante hacer notar que las luchas colectivas de las maestranzas derivan en crisis que, a la postre, terminan afectando la supuesta armonía de la ciudad en su conjunto. De lo anterior, es posible establecer que la decadencia del puerto se instala en Valparaíso tras el advenimiento de una crisis económica que azota con fuerza a los sectores más empobrecidos. Esta situación desemboca en una gran tensión social que se manifiesta en las calles, dando paso a confrontaciones entre los trabajadores y la guardia civil. Así, por ejemplo, se aprecia en la novela de 1933:

Valparaíso despertó bajo una pauta de inquietantes expectativas. La huelga de los obreros marítimos se había convertido en una huelga general. Los servicios de la ciudad se hallaban suspendidos; ni los tranvías circulaban. Patrullas de soldados vigilaban las calles, las plazas y los edificios públicos. Los desfiles de manifestantes arrollaban al transeúnte, impeliéndolo a engrosar la fila. [...] En esas circunstancias renunció el Ministerio y se implantó la dictadura. No tardó en proclamarse el estado de sitio. El puerto iba a presenciar un espectáculo bárbaro, a base de masacres, descargas cerradas contra la muchedumbre y arbitrarias persecuciones. (65)

Bajo esta perspectiva, es posible sostener que el Valparaíso de Danke puede ser leído como una "ciudad anárquica”, concepto que constituye un oxímoron y una alusión. Es oxímoron porque relaciona y reconcilia elementos contradictorios generando un nuevo sentido. Si el concepto de ciudad, y en especial la ciudad latinoamericana, ha sido asociado tradicionalmente a la noción de orden ${ }^{6}$, la "anarquía”, que etimológicamente proviene del griego y significa sin gobierno, se vincula con la idea de caos político, desorden y libertad. De esta forma, la "ciudad anárquica” tiene que ver con la construcción de un espacio urbano donde prima un orden pusilánime, en el que el caos desafía permanentemente a las estructuras sociales, culturales y políticas, transgrediendo las múltiples directrices que siguieron parte

${ }^{6}$ En Ciudad, género e imaginarios urbanos en la narrativa latinoamericana (2014) Lucía Guerra establece que la ciudad es "el locus, por excelencia, de la producción y circulación del orden social y político implementado por una estructura de poder” (12). 
importante de las urbes continentales. Valparaíso tiene una serie de características y rasgos que cuestionan la conformación ordenada de la ciudad latinoamericana.

Valparaíso se transforma en una "ciudad anárquica" por la coyuntura política, económica y social que experimenta la ciudad en ese periodo, coyuntura que genera, por cierto, una transformación en la identidad colectiva de la urbe. Así, la ciudad no podrá superar los efectos de esa crisis en las siguientes décadas. Principalmente, porque la crisis deviene en el abandono del espacio urbano tanto a nivel de la ciudadanía como del poder económico, tal como el propio Danke anuncia en La estrella roja:

\begin{abstract}
Empezó, imperceptiblemente primero, con caracteres alarmantes después, el éxodo de los habitantes a la capital y a los originales pueblos sureños en donde se aseguraba que la catástrofe económica se dejaba sentir con menor intensidad y crudeza. La prensa misma se mostraba desconcertada y dubitativa; de nada servían sus llamados a la serenidad y la paciencia, pues la desastrosa falta de trabajo, el descenso fantástico de la moneda y el alza de los precios en los artículos de consumo, la desmentían en forma por demás terminante e incontestable. Empezó el éxodo en busca de perspectivas menos hostiles, y la antigua y proverbial prosperidad del puerto más importante de la República, se derrumbaba inevitablemente, como un edificio al cual se le hubiesen socavado en corto tiempo los cimientos. (1936: 111-112)
\end{abstract}

Tanto los habitantes como las firmas empresariales se trasladan a Viña del Mar y, mayoritariamente, a Santiago. Para Eduardo Cavieres, este segundo fenómeno contribuye a consolidar la crisis económica de Valparaíso. Ciertamente, el deterioro de las expectativas financieras tiene impacto tanto en en el crecimiento discreto de la población como en el deterioro urbano. En nuestra perspectiva, estos desplazamientos pueden ser leídos a partir de una idea que Magda Sepúlveda desliza en Ciudad Quiltra. Poesía Chilena (1973-2013) en orden a que: "podemos pensar las modificaciones de las ciudades chilenas como parte de un imaginario social del progreso que va generando la ruina de otro espacio" (2013: 17). El aporte de Sepúlveda es clave para comprender que el derrumbe del puerto depende de manera directa del ascenso de la metrópoli. La concentración del poder político y económico en Santiago, desde el segundo tercio del siglo XX, incide en el declive de Valparaíso. 


\section{Conclusiones}

La narrativa de Jacobo Danke evidencia un marcado distanciamiento frente a la idealización de una ciudad próspera, cosmopolita y oligarca, propia de la idea del "Valparaíso sublime" descrito por Joaquín Edwards Bello. Danke desmantela, más bien, la imagen uniforme y homogénea de la ciudad, poniendo en crisis el imaginario urbano decimonónico y de las primeras décadas del siglo XX, delineando un espacio urbano marcado por las tensiones políticas, sociales y económicas. Asimismo, visibiliza las demandas laborales lideradas por los obreros y los portuarios.

En la elaboración del imaginario urbano porteño, Danke opta por una perspectiva grisácea, nebulosa y fría, pues, para el escritor, pareciese fundamental esbozar los escenarios miserables de un puerto en decadencia, el que, inexorablemente, trae recuerdos de la explotación capitalista en el Londres victoriano. Todo lo anterior contribuye a transformar la otrora "ciudad liberal" en una "ciudad anárquica" signada por el desorden, los conflictos sociales y la liberalización de la multitud, la que, por cierto, reivindica derechos que, históricamente, fueron negados por el poder gobernante.

Al tratar un periodo de crisis social, política y económica, Danke advierte la profundización de la fisura existente entre Valparaíso y Santiago. Si ya a inicios del siglo XX existía una oposición identitaria entre ambas ciudades, la que, tal como advierte Roberto Hozven en su lectura de El roto y La cuna de Esmeraldo, se aprecia al considerar a la capital como "baluarte colonial, clerical y reaccionario" (Cit. en Hozven 2006: 6) y a Valparaíso como una ciudad "liberal, enemiga del caciquismo santiaguino" (Cit. en Hozven 2006: 6); los sucesos acaecidos tras la crisis de 1929 agravan la distancia entre ambas urbes. Así, mientras Santiago se convierte en el eje del poder político y económico de Chile, Valparaíso se deteriora de manera progresiva hasta sumirse, al menos parcialmente, en la ruina.

En efecto, se podría considerar que es a partir de esta época que comienza a consolidarse en Valparaíso la construcción de una literatura menor, esto es, la literatura que "una minoría hace dentro de una lengua mayor" (Deleuze y Guattari, 2002: 26), es decir, la literatura que surge en Valparaíso y que se efectúa en relación a la realidad nacional hegemonizada por Santiago. De esta forma, la literatura de/sobre Valparaíso horada, 
parafraseando a Deleuze y Guattari, a la construcción identitaria metropolitana, generando una propuesta política disidente respecto de la forma de entender las representaciones urbanas estatuidas a nivel nacional.

\section{Referencias}

Danke, Jacobo. (1933). Dos hombres y una mujer. Memorias de un proletario. Santiago: Ercilla. . (1936). La estrella roja. Santiago: Ercilla. . (1974). Danke, Jacobo. Onomatopeya portuaria. En Guzmán, Nicomedes. Autorretrato de Chile. Santiago: Zig-Zag.

De Certeau, Michel. (2010). La invención de lo cotidiano 1. Artes de hacer. México DF: Universidad Iberoamericana.

Deleuze, Gilles y Guattari, Félix. (2002). Kafka. Para una literatura menor. Madrid: Editora Nacional.

Edwards Bello, Joaquín. (1986). Magia de Valparaíso. Atenea, 453-454, 127-131.

Fernández, María Isabel. (2012). Los cuentos de Valparaíso: el porteñismo como una práctica discursiva motivada por la experiencia espacial. Tesis inédita de la Pontificia Universidad Católica de Valparaíso, Valparaíso, Chile.

Foucault, Michel. (2008). Historia de la sexualidad. La voluntad de saber. Buenos Aires: Siglo veintiuno editores.

García Canclini, Néstor. (1995). Consumidores y Ciudadanos. Conflictos multiculturales de la globalización. México: Editorial Grijalbo. . (1999). Imaginarios urbanos. Buenos Aires: Eudeba.

Guerra, Lucía. (2014). Ciudad, género e imaginarios urbanos en la narrativa latinoamericana. Santiago: Editorial Cuarto propio.

Guerrero, Leoncio. (1963). La novela reciente en Chile. Journal of interamerican studies, 3, 379-395.

Herrera, Tania y Farga, Victorino. (2015). Historia del Programa de Control de la Tuberculosis de Chile. Revista Chilena de Enfermedades Respiratorias, 31, 227-231. 
Hozven, Roberto. (2006). La ciudad de Santiago en el sentir de Joaquín Edwards Bello y de Jorge Edwards. Revista Chilena de Literatura, 69, 5-23.

Kafka, Franz. (2014). Obras completas II. Barcelona: Olmak Trade.

Latcham, Ricardo. (1945, 20 de mayo). Crónica literaria: La taberna del perro que llora. La Nación, s/n.

Mondaca, Julio. (1957). Evocación a Jacobo Danke. Atenea 376,195-200.

Nordenflycht de, Adolfo. (2011). Valparaíso como espacio de aventura en el imaginario de la narrativa imaginista. Atenea 504, 55-72.

Orlandi Araya, Julio. (1946). Valparaíso a través de la literatura. Anales de la Universidad de Chile 63-64,105-246.

Osses, Mario. (1952, 14 de diciembre). Crítica literaria: Todos fueron de este mundo. La Nación, s/n.

Plath, Oreste. (1939, 13 de agosto). "Quien es quien en la literatura chilena”. La Nación, s/n.

Reyes, Salvador. (1956). El continente de los hombres solos. Santiago: Ercilla.

Rojo, Grínor. (2006). Globalización e identidades nacionales y postnacionales... ¿de qué estamos hablando? Santiago: Lom.

Sabella, Andrés. (1946, 29 de mayo). Cuaderno de bitácora de Jacobo Danke. La Nación, s/n.

Sepúlveda Eriz, Magda. (2013). Ciudad Quiltra. Poesía Chilena (19732013). Santiago: Editorial Cuarto Propio.

Silva, Armando. (2000). Imaginarios urbanos. Bogotá: Editorial Tercer Mundo.

. (2003). La ciudad como arte. Recuperado de: http://dialogosfelafacs.net/wp-content/uploads/2015/47/La-ciudad-como-arte. pdf [10 May. 2003)

Silva Castro, Raúl. (1945, 5 de marzo). Crónica de letras: La taberna del perro que llora. Las últimas noticias, s/n. - (1960). Historia crítica de la novela chilena (1843-1956). Madrid: Cultura hispánica. 